\title{
QUANDO O BRINCAR TEM HORA E LUGAR: REFLEXÕES SOBRE O USO DO PARQUE NA EDUCAÇÃO INFANTIL
}

\author{
Aliandra Cristina Mesomo Lira* \\ Josiane Aparecida Kopczynski**
}

\begin{abstract}
Resumo: O objetivo do artigo é problematizar o uso do parque nas instituições de educação infantil, refletindo sobre o papel do brincar na formação das crianças. A reflexão é resultado de pesquisa que buscou identificar como estava organizado o parque de uma instituição de educação infantil e quando ele era utilizado pelas crianças, bem como quais brincadeiras eram vivenciadas por elas nesse espaço. Foi possível reconhecer que o uso do parque faz parte de um cotidiano extremamente dirigido e controlado pelo adulto, desde a disposição dos brinquedos até a existência dos horários de parque nas rotinas das turmas.
\end{abstract}

Palavras-chave: Infância. Brincadeiras. Parque. Disciplinamento.

\section{When playing has time and place: reflections about the use of playgrounds in childhood education}

Abstract: The objective of this article is to problematize the use of playgrounds in
childhood education institutions, reflecting about the role of playing in the formation
of children. The reflection is a research that attempted to identify how the playground
of a childhood education institution was organized and when it was used by children,
as well as which games were experienced by the children in this space. It was possible

\footnotetext{
* Doutora em Educação pela Universidade de São Paulo; Professora da Universidade Estadual do CentroOeste; Rua Domingos Marcondes, 1514, Santana, 85070-020, Guarapuava, Paraná, Brasil; aliandralira@ gmail.com

** Graduada em Pedagogia pela Universidade Estadual do Centro-Oeste; Membro do Grupo de Estudos e Pesquisas em Educação Infantil da Universidade Estadual do Centro-Oeste; Rua Domingos Marcondes, 1514, Santana, 85070-020, Guarapuava, Paraná, Brasil; josinha_ak@hotmail.com
} 
to recognize that the use of this playground is part of a routine extremely directed and controlled by adults, since the arrangement of the rides, even the existence of a playground schedule in the groups' routines.

Keywords: Childhood. Games. Playgrounds. Disciplining.

\section{INTRODUÇÃO}

É uma bela tarde de sol. Depois de uma série de atividades no papel, nas mesas e cadeiras, o grupo de crianças de 2 e 3 anos ouve da professora: "Chegou a hora do parque. Agora vocês podem brincar." Apressadamente, com alegria e euforia, as crianças posicionam-se perto da porta e aguardam a professora para acompanhá-las até o espaço externo. Vão conversando entre si, já combinando suas brincadeiras. Ao chegarem, espalham-se rapidamente, formam pequenos grupos. Algumas brincam nos brinquedos, outras conversam entre si, negociam, correm. O tempo passa rápido e, logo, a professora anuncia que devem voltar para a sala. Os corpos resistem, brincam um pouquinho mais. Enfim, entregam-se, e, enfileiradas, as crianças voltam para a parte interna da instituição.

A descrição anterior resume, em poucas linhas, um dos momentos de brincadeira no parque vivenciado em nossa pesquisa. A experiência relatada, com algumas pequenas variações, reflete as observações que fizemos em uma instituição de educação infantil. A organização e a vivência da brincadeira no espaço externo foram o foco de nossa investigação e merecem reflexão, uma vez que as crianças, desde pequenininhas, têm demarcados o tempo e o espaço do brincar institucionalmente, situação que relega a brincadeira a segundo plano e traz à tona a urgência e a necessidade de se repensar o brincar no cotidiano da educação infantil.

Partimos do pressuposto que a brincadeira, como atividade expressiva, pode desenvolver a criatividade, a expressão, a comunicação e a imaginação, além de promover a socialização. Na educação infantil, o brincar é reconhecido como o eixo do trabalho educativo, devendo permear as atividades que as crianças realizam e participam durante o dia. A partir desse entendimento, os espaços e os momentos institucionais deveriam estar organizados de maneira a permitir a expressividade da criança por meio do brincar. Os espaços externos, como parques, precisam estar equipados com materiais adequados, além de dispor de generoso espaço livre que permita brincadeiras.

Considerando essas necessidades, buscamos identificar como estava organizado o espaço externo de uma instituição de educação infantil, quais equipamentos/ brinquedos comportava e como as crianças organizavam suas ações em razão dos 
materiais e do tempo de que dispunham. Com esse intuito, realizamos observações sistemáticas, durante quatro meses, do espaço externo, mais precisamente do parque, quando ocupado por um grupo de crianças de 2 e 3 anos de idade, em uma instituição pública do município de Guarapuava, PR. Para tanto, nos dias em que a turma tinha tempo destinado ao parque, sempre de acordo com o cronograma da instituição, foram feitas observações, sendo os dados mais relevantes descritos em diário de campo. Nosso olhar esteve guiado pela compreensão da criança enquanto um sujeito ativo no seu processo de desenvolvimento e aprendizagem, como alguém capaz e, por isso, não apenas aquele que se adapta ao ambiente, mas que tem condições de nele intervir, que vivencia e absorve elementos da cultura, especialmente a cultura infantil, reconstruindo-a e reorganizando-a, desde que as condições lhe sejam favoráveis.

\section{A RELAÇÃO ENTRE A INFÂNCIA, AS BRINCADEIRAS E A EDUCAÇÃO}

De forma geral, os jogos, brinquedos e brincadeiras fazem parte da vida das crianças, nas famílias ou nas instituições educativas. Em casa, os pais e outros adultos da família compram, dentro de suas condições, brinquedos e jogos pensando no divertimento das crianças. Nas instituições responsáveis pela educação das crianças, principalmente de educação infantil, também encontramos razoável quantidade de materiais lúdicos que deveriam estar disponíveis às crianças. Assim, embora esporádicos, podem ser observados momentos de brincadeira dos adultos com as crianças e das crianças entre si, tanto nas casas quanto nas instituições responsáveis por sua educação.

Podemos dizer, então, que tanto as crianças mais favorecidas economicamente quanto aquelas de famílias com menor poder aquisitivo, em alguns momentos de seu dia, brincam. Os materiais diferenciam-se, mas, em geral, quando podem, as crianças encontram maneiras e inventam brinquedos para se divertir. É preciso considerar que, em ambos os grupos, a mídia tem um importante papel na escolha dos brinquedos e na condução das brincadeiras, criando desejos e tornando o entretenimento infantil um negócio lucrativo.

Nesse sentido, quando falamos em brinquedos e brincadeiras na esfera educacional, precisamos refletir sobre quais materiais estamos oferecendo às crianças, que tipo de brincadeiras eles proporcionam ou nós adultos professores vivenciamos com elas; jogar e brincar têm um importante papel na formação e no desenvolvimento infantil. Os brinquedos escolhidos para brincar, os espaços organizados para a brincadeira e o tempo disponível para as atividades lúdicas nas instituições conformam as identidades 
infantis de maneiras diferenciadas, uma vez que os objetos e práticas, em geral, são usados e organizados pelos professores com fins pedagógicos específicos e predefinidos.

Quando pensamos em brinquedos e brincadeiras imediatamente nos lembramos das crianças; contudo, essa associação não pode ser pensada de forma tão naturalizada. Como, acertadamente, aconselha Bujes (2005, p. 187), “Uma investigação sobre a infância e os fenômenos que a ela se associam deve se centrar não no que ela e eles são, mas como se constituíram de tal maneira." Assim, os jogos e as brincadeiras, como atividades associadas à infância, requerem sempre uma atenção especial e precisam ser investigados em seus múltiplos aspectos.

É preciso assinalar que o caráter lúdico que envolve os jogos e as brincadeiras não os isenta das relações de poder. Segundo o filósofo francês Foucault (2003, 2005), não existe situação - de brincar ou não - que não esteja visceralmente comprometida com o poder. Quanto às práticas relacionadas ao brincar, quando definimos/escolhemos brinquedos, quando vigiamos as ações, quando as controlamos e dirigimos, quando delimitamos o tempo de brincar, o brinquedo, as brincadeiras e os jogos estão permeados pelo poder.

É na modernidade e pela via da Psicologia que a produção do discurso sobre o jogo e o seu potencial se articulam às crianças e ao campo educacional. Como aponta Bujes (2002), em sua análise, os discursos que descreveram a infância contribuíram para desencadear estratégias para governá-la. Assim, falar de brinquedo e brincadeiras e relacioná-los às crianças significa construir um discurso que tem um amplo papel na constituição dos sujeitos e, como nos ensinou Foucault, está comprometido com o exercício do poder.

Certamente é Foucault (2003) quem nos ajuda a entender a verdade como um empreendimento ligado, em primeiro lugar, a sistemas de poder-saber que, ao mesmo tempo que a produzem, apoiam-na, estando também relacionada a efeitos de poder por ela induzidos e que a multiplicam - regimes de verdade. O papel político que a verdade desempenha se deve ao fato de que ela não existe fora do poder ou sem poder, sendo produzida a partir de múltiplas coerções e gerando efeitos regulamentados de poder. Cada sociedade acolhe um tipo de discurso e o faz funcionar como verdadeiro, a partir, também, daqueles que têm o poder de dizer o que funciona. Entre as características da "economia política" da verdade, Foucault aponta que ela é centrada na forma do discurso científico e nas instituições que o produzem, sendo objeto de grande difusão e imenso consumo, circulando, por exemplo, nos aparelhos de educação. Diante disso, o importante, a partir dessa compreensão, é ver historicamente como se criam efeitos de verdade no interior dos discursos. 
Isso permite afirmar que o discurso sobre os jogos e o brincar construído na trama histórica da modernidade e associado à infância, constituiu-se, potencialmente, para propagar a educação. Assim, sendo inseridos nas instituições educativas, sob a supervisão e a orientação do adulto responsável pela educação das crianças, eles alcançaram resultados satisfatórios em termos de aquisição de noções, letras e números. Portanto, é preciso, pois, como nos incentivou Foucault (2005), analisar esse discurso como um acontecimento, determinar as condições de sua existência e estabelecer as correlações com outros enunciados, mostrando as exclusões e sua condição de importância.

Foucault (2003) problematiza as diversas formas e os arranjos sociais empregados para governar (manter sob controle), por meio do exercício do poder, diversos grupos sociais, incluindo a população escolar. Controle, aqui, entendido como governo sobre os corpos e mentes, com procedimentos específicos e instrumentos diversos, como o jogo/brincar, nesse caso. Segundo o autor, o poder é difuso, não está circunscrito a uma pessoa, mas sempre presente nas relações, perpassando espaços, tempos e práticas institucionais, inclusive as escolares.

Ao estudarmos a pedagogia froebeliana, ${ }^{1}$ reconhecemos como os jogos, brinquedos e brincadeiras foram normatizados, estruturados, descritos e comentados, ganhando, a partir do século XX, espaço nas instituições escolares para crianças pequenas e podendo ser reconhecidos como dispositivos pedagógicos de controle e disciplinamento da infância. Seguindo o entendimento de Foucault (2003), ao agirem sobre a ação das crianças, ao dirigirem comportamentos, produzem reações, induzem, direcionam, o que qualifica o poder como produtivo e não apenas restritivo.

Segundo Brougère (2001), o valor educativo associado aos jogos está ligado ao movimento romântico, que ajudou a consolidar uma imagem positiva e valorosa da criança, e também à Psicologia, que buscou apresentar argumentos científicos dos benefícios da relação entre educação e brincadeiras. Ao apontar a origem de tal associação, o autor não desconsidera que os jogos e as brincadeiras podem facilitar o desenvolvimento, inclusive quando têm declaradamente propósitos educativos, mas alerta que os efeitos são menores daqueles propalados.

Em outro estudo, Brougère (2003) destaca que o movimento da Escola Nova ajudou a instaurar e a sedimentar a modernidade pedagógica que inclui o jogo. Baseada na Psicologia, a educação renovada expressou uma justificação quase biológica (natural) para o papel do jogo na escola, abrindo espaço a ele para satisfazer às crianças e às suas necessidades, atribuindo-lhe um valor educativo.

Percebemos, com isso, como os enunciados da Psicologia conformaram o discurso pedagógico, formando o que Foucault (2005, p. 74) chamou de "campo de 
concomitância", isto é, suas premissas são aceitas para o raciocínio e valem como conformação analógica. As estratégias de reforço e dispersão são destacadas pelo autor que sugere descrever " [...] o papel desempenhado pelo discurso estudado em relação aos que lhe são contemporâneos e vizinhos [...]”, posto que podem estar em uma relação de complementaridade com outros discursos.

Segundo Bujes (2000), assentadas no desenvolvimento da criança descrito pela Psicologia, as práticas com os sujeitos infantis privilegiam os jogos e as brincadeiras como aparatos pedagógicos, especialmente propícios ao trabalho com as crianças em propostas de ensino que almejam a aprendizagem de condutas, comportamentos e também de conceitos e noções científicas.

Rose (2001) afirma que a subjetividade é constituída por meio da ligação dos sujeitos a outros objetos e práticas, multiplicidades e forças. Nos diferentes contextos e situações, e por meio de variadas formas de relacionamento, o sujeito é produzido e, para entender como chegamos a ser o que somos, o autor sugere a análise das técnicas, das intensidades, das autoridades e dos aparatos operantes na sociedade e em suas instituições. Segundo Dornelles (2005), é principalmente nas instituições educativas que o funcionamento do poder produz as almas dos que são vigiados, corrigidos, treinados.

\section{O BRINCAR E A EDUCAÇÃO INFANTIL}

As discussões em torno da educação infantil - primeira etapa da educação básica, que atende a crianças de 0 a 5 anos - apresentam, entre outros aspectos, a importância do brincar para o desenvolvimento infantil. As pesquisas e as orientações oficiais são enfáticas ao afirmar que o trabalho de cuidado-educação a ser desenvolvido com as crianças deve ter como eixo principal o brincar. Esse olhar positivo sobre o brincar entende que as práticas pautadas na ludicidade promovem o desenvolvimento das crianças nos diversos aspectos - cognitivo, social, afetivo, físico e psicológico.

Entendemos também que o brincar pode trazer contribuições ao desenvolvimento das crianças de 0 a 5 anos de idade, uma vez que por meio das brincadeiras elas resolvem conflitos, usam a imaginação, negociam encaminhamentos e socializam-se, ao aprender a lidar com diferentes situações e pontos de vista. Todas essas habilidades fazem parte de contextos de brincadeira quando as crianças têm a oportunidade de vivenciar espaços amplos, ricos em materiais e também têm autonomia para encaminhar suas brincadeiras. Assim, é necessária uma "certa"2 liberdade para as crianças organizarem o brincar. 
Bujes (2000) destaca que os materiais para brincar, em geral, são considerados como elementos desestabilizadores do ambiente, potencialmente desarticuladores das relações e das normas de conduta; por isso de as instituições educativas se valerem de um regramento em relação a esses objetos.

Sobre os brinquedos infantis privilegiados, Perroti (1990, p. 98) considera que "[...] quando os produtos da cultura aparecem associados a um quadro de confinamento, eles passam a atuar sobre um vazio significativo e assumem o papel de preencher sentidos." Dornelles (2003, 2004) considera o brincar como envolto em interesses e imposições culturais e aponta que, historicamente, as crianças da educação infantil vêm tendo acesso apenas a certos tipos de brinquedos e que isso, certamente, produz efeitos na constituição das subjetividades infantis. Determinados artefatos estimulam ações particulares e induzem a interpretações que coincidem com os interesses daqueles que os produzem.

Nos espaços institucionais - sala de atividades, brinquedoteca, biblioteca, pátio, parque - os materiais disponíveis e as atividades permitidas podem evidenciar ou não a ação sobre as condutas das crianças. Como assinala Bujes (2000), ao definirmos/escolhermos o brinquedo adequado para o momento e suas ações possíveis, o desenvolvimento permitido é limitado e conformado.

Compreende-se, pois, que é o investimento, a lógica educacional calcada nas orientações da Psicologia, que atribui significações diversas aos jogos e às brincadeiras, de acordo com seus usos ou orientações para uso, estas apoiadas em intencionalidades no que se refere à formação dos sujeitos infantis. A partir disso, a maneira com que os professores encaminham as brincadeiras, a forma como disponibilizam os brinquedos no espaço institucional, enfim, os sentidos atribuídos ao brincar têm papéis diferentes na constituição das subjetividades das crianças. Práticas estritamente controladas, planejadas e dirigidas, bem como brinquedos guardados em grandes armários, revelam uma concepção de que o brincar precisa ser constantemente vigiado.

Segundo Huizinga (2001), como manifestação autêntica e espontânea, o jogo carrega o gosto pela ação, pela participação consentida e por uma diretividade, no campo da educação, que deve ser mediada e não imposta. Kishimoto (2001) salienta que os jogos e as brincadeiras têm um fim em si mesmo, ou seja, por si só já são educativos, podendo ou não se associar ao ensino de determinados conteúdos e noções.

Contudo, a compreensão da importância do lúdico para o desenvolvimento infantil não é suficiente para garantir que os jogos e as brincadeiras façam parte da prática pedagógica com as crianças. Por acreditar que a criança aprende quando se dedica a atividades de leitura, escrita e cálculo registradas no papel, nos cadernos e 
apostilas, a maioria dos professores acaba por deixar as brincadeiras e os jogos para momentos esporádicos ou para o recreio, incorporando, dessa forma, apenas no nível do discurso a ludicidade como impulsionadora do desenvolvimento e da aprendizagem. Na prática predomina, desde os primeiros anos de vida, uma escolarização que negligencia a infância e a importância que a ludicidade tem para ela.

Carneiro (2010, p. 29) alerta que é preciso incorporar e praticar a ludicidade nas instâncias formadoras dos profissionais da educação, sem restrições, buscando alterar a situação de marginalização que se apresenta em relação ao brincar:

\begin{abstract}
Nunca se falou tanto sobre a importância do brincar, o seu valor para o desenvolvimento e aprendizado da criança e sobre o seu valor na perspectiva do resgate cultural. Também nunca se preconizou tanto a atividade lúdica, enquanto um direito da criança e a garantia de uma cultura da infância, mas, talvez ele nunca tenha sido tão desprezado do ponto de vista da prática.
\end{abstract}

No entender da autora, há concordâncias entre os pesquisadores e os professores sobre a importância das brincadeiras e dos jogos para o desenvolvimento e aprendizagem das crianças, todavia, ainda prevalecem o preconceito e a desinformação quanto às práticas lúdicas.

\title{
4 QUANDO E COMO SE BRINCA NO PARQUE
}

A dinâmica das práticas pedagógicas na educação infantil era, em parte, conhecida por nós por meio dos estágios e pesquisas desenvolvidas no Curso de Pedagogia, contudo, importava determo-nos com mais atenção ao brincar que acontecia no parque, a fim de identificar quando e como ele ocorria. Nossas observações aconteceram, de forma sistemática, em uma instituição de educação infantil pública, do município de Guarapuava, PR, e foram reveladoras do lugar que o brincar ocupa no cotidiano das crianças institucionalizadas.

A instituição atende a seis turmas, com mais ou menos 25 crianças cada, que permanecem em média oito horas na instituição. Cada uma das turmas tem dias e horários específicos para ir ao parque e, de acordo com o cronograma, as crianças podem brincar no parque duas vezes na semana, por aproximadamente uma hora. Em dias chuvosos ou muito frios, a saída para o espaço externo não acontece, sendo importante registrar que a instituição não dispõe de nenhum outro espaço coberto, de uso coletivo, para brincadeiras. Segundo as professoras, é necessário que sejam rigorosas no cumprimento dos horários disponíveis para o uso do parque, a fim de garantir que todas as turmas brinquem. 
Richther e Vaz (2010, p. 4) refletem sobre a racionalidade que se exerce nos momentos de parque em uma rotina de educação infantil:

[...] um ambiente planejado e preparado para abrigar crianças de acordo com a faixa etária, demarcado por cercas, mobiliário, equipamentos, tal como se estrutura uma sala de aula. Conta-se com a presença de crianças no parque em horários definidos, que podem ser negados aos pequenos como ameaça ou castigo que se concretiza caso 'boas condutas' não sejam retomadas. Nesse quadro, podemos dizer que, embora considerado como espaço de criação e liberdade, o parque se coloca como extensão da sala e como estratégia de intervenção [...]

Kohan (2003, p. 79) explicita como a disciplina e a regulação se expressam nas experiências vivenciadas pelas crianças nas escolas:

Nas escolas, os indivíduos não fazem qualquer coisa, em qual-
quer momento, em qualquer lugar. Os espaços são cuidado-
samente delimitados, o tempo é marcado por um cronograma
preciso, regular e regulado, os aprendizados são organizados
em etapas, de forma tal a exercitar em cada período, um tipo
de habilidade específica. Um conjunto de formas reguladas de
comunicação (lições, questionários, ordens, exortações, sinais
codificados de obediência) e um conjunto de práticas de poder
(clausuramento, vigilância, recompensas e punição, hierarquia
piramidal, exame) conformam o campo do que é possível per-
ceber, dizer, julgar, pensar e fazer na instituição escolar.

Percebemos que, considerado o número de crianças atendidas pela instituição, um parque é insuficiente para que elas brinquem no espaço externo, uma vez que seria desejável que todos os dias pudessem brincar em outro espaço que não o da sala de atividades. Outro agravante é a inexistência de um espaço coberto, no qual poderiam ser desenvolvidas brincadeiras nos dias mais frios e chuvosos. A importância do brincar nesses espaços mais amplos é mais relevante ainda, uma vez que nas salas, onde as crianças permanecem a maior parte do tempo, o espaço é quase totalmente tomado por mesas e cadeiras, principalmente no caso das crianças maiores (no berçário, são os berços que ocupam grande parte da sala).

Para efeito de nossa pesquisa, observamos uma turma de Jardim I, que integra 17 crianças com idade entre dois e três anos, nos momentos em que estavam no parque da instituição. Segundo a professora da turma observada, além de irem ao parque duas vezes por semana, as crianças vão uma vez por semana para a casinha, que fica separada do parque, e também uma vez por semana para o solário.

O parque encontra-se em espaço razoavelmente amplo, sendo o solo coberto por grama, com exceção de algumas partes com terra, em que as crianças 
permanecem por mais tempo, inclusive em uma parte com elevação (pequeno morro). Esse dado é interessante, pois percebemos que, recorrentemente, as crianças agrupavam-se para brincar na terra, cavar, escorregar, entre outras atividades. $\mathrm{O}$ ambiente, de forma geral, poderia favorecer e intensificar o contato com a natureza, porém, das três árvores presentes, duas são cercadas por muretas que acabam por limitar o acesso das crianças a elas.

Segundo Horn (2004), a organização dos espaços pode beneficiar a construção do conhecimento, promovendo, além de outras contribuições, a autonomia corporal e a espontaneidade da criança. Todavia, a autora ressalta que, quando a interferência e a vigilância do adulto são constantes, o espaço torna-se elemento repressor e reprodutor de uma educação disciplinadora e controladora.

Em relação aos brinquedos, havia um trem com cabine de madeira e vagões de manilhas preenchidas com concreto; os degraus que davam acesso à cabine eram de tijolos assentados. Havia também um túnel de manilhas, um túnel feito de pneus, três balanços, um gira-gira, duas gangorras e uma estrutura para balanço, mas sem os balanços. Outro brinquedo era uma estrutura em que as crianças podiam subir por uma armação vertical de ferro e descer pelo outro lado do brinquedo por meio de um escorregador. Embaixo dessa estrutura, havia um balanço de pneu, uma gangorra de madeira, duas argolas para as crianças se pendurarem e uma escada que se movia, todos presos por correntes de ferro. De forma geral, os brinquedos apresentavam bom estado de conservação e manutenção, com pintura colorida um tanto danificada.

Durante as observações, identificamos que, entre os brinquedos, aqueles que mais favoreciam o contato entre as crianças eram o trem e os túneis, nos quais elas se concentravam em maior número. No trem, raríssimas vezes notamos a presença das meninas, tratava-se de um brinquedo predominantemente ocupado por crianças do sexo masculino; os meninos brincavam dizendo estar indo para o trabalho ou para a escola, etc. Entretanto, por ser a cabine do trem um espaço muito desejado, porém pequeno, que comportava no máximo três crianças, quando outras se aproximavam o brinquedo se transformava em palco de muitos conflitos, estes resolvidos prontamente pela intervenção da professora, que dizia quem podia brincar antes ou depois. Essas situações poderiam permitir que as crianças resolvessem entre si os impasses, estando a professora apenas como mediadora.

Nos túneis, as crianças aproveitavam melhor a companhia dos colegas, pois geralmente suas brincadeiras se organizavam da seguinte maneira: uma das crianças permanecia ao lado de fora do túnel e fingia ser um "monstro", ou algum animal feroz, enquanto as demais, que ficavam lá dentro, gritavam eufóricas e riam muito. Porém, 
vale ressaltar que, mesmo sendo esse brinquedo um dos pouquíssimos que enriqueciam a socialização das crianças, a professora intervinha o tempo todo, para alertá-las que se cuidassem e principalmente para que não fizessem "tanto barulho". Os brinquedos ficavam próximos às janelas da sala do berçário e, em alguns momentos, a professora pedia às crianças que fossem brincar em outro espaço. Essas situações evidenciaram um problema de planejamento em relação à disposição dos brinquedos no parque, uma vez que, por estarem perto da sala onde permanecem os bebês, as crianças tinham suas brincadeiras, nesses equipamentos, controladas e limitadas.

Nos demais brinquedos em que a presença das professoras era constante, como balanços, gira-gira e outros, as crianças quase não conversavam e os diálogos entre professoras e crianças ocorriam principalmente no pedido dos pequenos para que os adultos os balançassem e empurrassem. Naqueles momentos, reconhecemos uma relação individual das crianças com os brinquedos que, embora acompanhadas pelas professoras, era bastante solitária.

De modo geral, em raros momentos, percebemos a proposição de outras brincadeiras ou a oferta de outros brinquedos e/ou materiais, por parte dos adultos, além dos brinquedos que são fixos do parque. Um fato que despertou atenção foi que, na turma, havia uma menina muito tímida, a qual ficava todo o tempo sentada em uma calçada, sem brincar nos brinquedos ou com as demais crianças. Durante as observações, não presenciamos conversas ou qualquer outra forma de interação das professoras com essa criança para que participasse das brincadeiras, permanecendo excluída e sozinha.

Brougère (1997, p. 64) destaca o papel do brinquedo na aprendizagem, afirmando que "[...] com o brinquedo, a criança constrói suas relações com o objeto, relações de posse, de utilização, de abandono, de perda, de desestruturação, que constituem, na mesma proporção, os esquemas que ela reproduzirá com outros objetos na sua vida futura."

Fundamentados nessa hipótese, salientamos a compreensão da importância de haver nas instituições brinquedos desafiadores os quais, ao mesmo tempo que explorem os movimentos, por exemplo, ofereçam segurança. Nesse sentido, reconhecemos que os brinquedos disponíveis não se diferenciavam dos que comumente são encontrados nos parques públicos.

De acordo com Dornelles (2001), a brincadeira constitui-se como algo pertencente à criança que, ao brincar, experimenta, organiza-se, constrói regras e desse modo descobre e compreende interativamente o mundo. No que diz respeito à nossa pesquisa, avaliamos que as crianças brincavam pouco, cerca de uma hora duas ve- 
zes por semana e quando não chovia. A realização de atividades nos espaços externos, a liberdade para brincar, agrupar-se, correr, deveria acontecer todos os dias, pois crianças tão pequenas que permanecem aproximadamente oito horas na instituição precisam vivenciar atividades fora dos limites das salas. Contudo, como em geral há apenas um parque nas instituições, é organizado um rodízio para o uso das turmas, o que acaba privando as crianças de um contato diário com esse espaço. Essa situação se agrava quando chove, pois o espaço físico interno não dispõe de local coberto para brincadeiras que não seja a sala de atividades de cada turma.

Ainda em relação aos brinquedos e às atividades no parque, percebemos que durante as brincadeiras as crianças quase não dialogam e não interagem entre si, prevalecendo um brincar isolado. Predomina a ânsia em aproveitar ao máximo o tempo de parque e, assim, elas acabam indo de um lado para o outro, de um brinquedo para o outro, rapidamente, querendo aproveitar o tempo que têm.

O parque é grande e as professoras reforçam a todo o momento que alguns brinquedos mais "perigosos" não podem ser utilizados e, dessa forma, observamos que as interações entre as professoras e as crianças se limitam a orientações sobre o que podem ou não fazer. Nesse espaço mais amplo e de "maior liberdade", a criança também precisa da mediação e da interação com a professora, porém os adultos entendem que sua participação deve se restringir à vigilância para afastar as crianças de locais inconvenientes. Richther e Vaz (2010, p. 2) apontam esse aspecto, também observado em seus estudos, e assinalam que "A ausência de uma aproximação mais cuidadosa acabará por deixar as crianças entregues à ambiguidade do 'espontâneo', expostas ao risco da violência que se materializa e permanece em marcas que se colocam, principalmente, sobre o corpo."

Beber (2014), ao pesquisar sobre as rotas de movimento das crianças pequenas no parque, problematiza o cuidado observado para que as crianças não se machuquem como uma situação de tensão entre a segurança a ser garantida e o controle do corpo empreendido pelas constantes interferências ou coibições manifestadas pelos professores. Em sua análise, destaca que o aprendizado sempre envolve riscos, mas as crianças constantemente tensionam as barreiras de segurança e, em nome da proteção, as regras que delimitam o uso do parque são muito bem delimitadas pelos adultos que, em geral, manifestam-se na reprimenda às iniciativas das crianças. Contudo, mais do que preservar a integridade física das crianças, as normas explicitadas pela rigidez das prescrições atuam sobre os corpos infantis os disciplinando e desconsideram as aprendizagens decorrentes das interações, do movimento. 
Essa contenção permanente, seja pelo tempo restrito de uso do parque seja pelo controle das ações, coloca as crianças na posição de dominadas, sob ameaças de que podem cair, machucar-se, bater, de que se não se comportarem não irão mais brincar no parque, entre outras falas. Nesse contexto, a espontaneidade e a liberdade praticamente inexistem em meio a comportamentos controláveis que reprimem "[...] tudo aquilo que de alguma forma se mostra desviante da racionalidade instrumental." (RICHTHER; VAZ, 2010, p. 2). Assim, as situações de controle e ordenamento da infância estendem-se a todos os espaços e momentos institucionais, desde a utilização do parque, já definida na rotina, como sobre os movimentos e ações das crianças enquanto brincam.

A disciplina direciona um comportamento esperado e coloca em funcionamento o exercício do controle por meio do olhar, das meias palavras, dos "gritos" de ordem, uma vez que o "[...] olhar disciplinador está sempre atento, olhando para cima e para baixo, intervindo continuamente, é perseverante, consequente, quotidiano e sistemático. É acima de tudo, vigilante." (ROCHA, 2000, p. 190).

Bizarro (2010, p. 14) relembra que "[...] se relega aos pátios uma condição secundária, que os mantém longe dos estudos sobre suas configurações", não sendo considerados como lugar educativo. Embora comumente seja mencionado, pelas próprias professoras, como espaço privilegiado de educação (RICHTHER; VAZ, 2010), o uso do parque e sua estruturação configuram uma rotina, por um lado, rigidamente controlada nos horários e movimentos e, por outro, carente de planejamento acerca do que poderia ser desenvolvido ali.

Um aspecto que merece ser ressaltado é que, a despeito das limitações de espaço, tempo e equipamentos, as crianças ainda se alegram quando chega o momento de "ir para o parque", uma hora desejada e aguardada. Embora se configure um espaço e tempo sujeitos a regulações, as resistências individuais e coletivas ganham mais espaço nos momentos de parque.

\section{CONSIDERAÇÕES FINAIS}

Partindo da constatação sobre a importância da educação infantil como primeira etapa da educação básica, e da criança como um sujeito de direitos, entendemos que as instituições precisam oferecer um espaço físico externo adequado à promoção do desenvolvimento infantil, aliado a um trabalho de qualidade. Segundo Dayrell (1996 apud KISHIMOTO, 2002, p. 27), "Quando há adequada estrutura arquitetônica acompanhada de oportunidades para a transformação e 
apropriação dos espaços, as crianças constroem conhecimentos, dando-lhes novos sentidos que moldam sua sociabilidade."

Os resultados da pesquisa apontam para a necessidade de se trabalhar com clareza a função socializadora da brincadeira no espaço externo da instituição de educação infantil, visto que os momentos no parque são muito desejados e prazerosos para as crianças.

Sobre os resultados da pesquisa, é possível encontrar amparo em Kishimoto (2002, p. 27) quanto observa que:

A valorização do brincar requer a partilha de concepções de criança e de educação infantil que privilegiem a expressão e a socialização nos cursos de formação inicial e continuada, retomadas pela equipe da escola, com apoio da família e da comunidade e de políticas públicas.

Nesse sentido, o investimento para a valorização do brincar precisa acontecer nos momentos de formação dos profissionais e, também, ser acompanhado por uma política de valorização do brincar na prática das instituições, com espaços amplos e ricamente organizados, a fim de atender a contento o número de crianças das instituições.

Esses encaminhamentos precisam se sobrepor às práticas que vigoram em muitas instituições de educação infantil, que ainda proporcionam um brincar extremamente diretivo e controlado, limitando a participação das crianças e a vivência das atividades e espaços lúdicos. Comumente, o brincar e as brincadeiras estão envoltos em discursos que destacam de forma inconteste seu papel positivo no desenvolvimento infantil. Vistos como atividades inocentes e mais ligadas ao mero entretenimento, um olhar acurado consegue identificar que, muitas vezes, os jogos e as brincadeiras não passam de forma despercebida pelas vidas das crianças, ou seja, desempenham um importante papel na constituição de suas subjetividades, suas formas de ser, pensar e agir no mundo. Como afirma Bizarro (2010), é preciso considerar que os pátios infantis nos subjetivam, tornam-nos sujeitos de suas possibilidades.

Por percebermos que o uso do parque tem dias e horários rigidamente estabelecidos, os brinquedos disponíveis são insuficientes e as brincadeiras das crianças são constantemente vigiadas e corrigidas pelos adultos que estão com elas, entendemos que a instituição de educação infantil e o brincar no parque conformam uma educação em um espaço de restrição e privação de liberdade. Bujes (2005) destaca que a criança e a infância são, cada vez mais, o foco de tecnologias de poder. Na escola, na família, com os amigos, pela mídia, pelo professor, pelos jogos ou pelas brincadeiras, as crianças são alvo constante dos discursos de verdade e dos artefatos que as 
constroem, modificam e governam; ou seja, esses discursos estão indubitavelmente permeados pelo poder.

Com a compreensão da importância do papel desempenhado pelos jogos, brinquedos e brincadeiras na constituição das identidades infantis, cabe aos professores organizarem práticas de brincar que permitam maior participação e escolha por parte das crianças, a exploração de seus movimentos e imaginação. Vivenciar e experienciar o brincar, de maneira prazerosa e criativa, colaboram para o desenvolvimento infantil em todos os aspectos e permitem que as crianças vivam a infância de forma mais plena. Atualmente, a valorização do lúdico no campo educativo também considera o jogar e o brincar como elementos políticos, ao suscitarem posicionamentos, tomadas de decisão, resolução de conflitos e problemas e confrontamento de opiniões. Essas questões precisam fazer parte da formação dos profissionais da educação, assim como o brincar precisa ser entendido e vivenciado como um momento de aprendizagem, crescimento e desenvolvimento, o que imprime um compromisso aos gestores da educação infantil com a formulação e a implementação de políticas de valorização do brincar nas instituições.

Notas explicativas

${ }^{1}$ Froebel foi o precursor dos jardins de infância e sua teoria foi apropriada e colocada em prática em diversos países nas experiências voltadas para a educação infantil, inclusive no Brasil. O primeiro jardim de infância público do país existiu em São Paulo, começando suas atividades em 1896, apoiado na pedagogia froebeliana. Contudo, análises da prática desenvolvida nessa experiência brasileira reconhecem que a ideia de jogo livre, defendida por Froebel foi deturpada entendemos que sempre haverá a participação do adulto, seja na disposição do espaço e dos materiais seja na indicação dos tempos de, predominando um uso do jogo extremamente diretivo e instrucional (MONARCHA, 2001; KUHLMANN JUNIOR, 2002; LIRA, 2009).

${ }^{2}$ A palavra está em destaque porque entendemos que sempre haverá a participação do adulto, seja na disposição do espaço e dos materiais, seja na indicação dos tempos de brincadeira mais livre, sendo, dessa forma, o brincar ligado ao adulto e envolto em relações de poder.

\section{REFERÊNCIAS}

BEBER, I. C. R. As experiências do corpo em movimento das crianças pequenas: reflexões para a pedagogia da infância. 2014. 194 p. Tese (Doutorado)-Universidade Federal do Rio Grande do Sul, Porto Alegre, 2014.

BIZARRO, F. de L. Em meio a infâncias e arquiteturas escolares: um estudo sobre os pátios da educação infantil. 2010. 105 p. Dissertação (Mestrado em Educação)-Universidade Federal do Rio Grande do Sul, Porto Alegre, 2010.

BROUGÈRE, G. Brinquedo e cultura. 2. ed. São Paulo: Cortez, 1997. 
BROUGÈRE, G. Brinquedo e cultura. São Paulo: Cortez, 2001.

BROUGÈRE, G. Jogo e Educação. Porto Alegre: Artmed, 2003.

BUJES, M. I. E. Criança e brinquedo: feitos um para o outro? In: COSTA, M. V. (Org.). Estudos culturais em educação. Porto Alegre: Ed. UFRGS, 2000.

BUJES, M. I. E. Infância e maquinarias. Rio de Janeiro: DP\&A, 2002.

BUJES, M. I. E. Infância e poder: breves sugestões para uma agenda de pesquisa. In: BUJES, M. I. E.; COSTA, M. V. Caminhos investigativos III: riscos e possibilidades de pesquisar nas fronteiras. Rio de Janeiro: DP\&A, 2005.

CARNEIRO, M. A. B. Memória e patrimônio: a cultura da infância e o brincar. In: CARNEIRO, M. A. B. (Org.). Cócegas, cambalhotas e esconderijos: construindo cultura e criando vínculos. São Paulo: Articulação Universidade Escola, 2010.

DORNELLES, L. V. Infâncias que nos escapam: da criança na rua à criança cyber. Petrópolis: Vozes, 2005.

DORNELLES, L. V. Na Escola Infantil todo Mundo Brinca se Você Brinca. In: CRAIDY, C. M.; KAERCHER, G.; SILVA, E. P. da. Educação infantil: pra que te quero? Porto Alegre: Artmed, 2001.

DORNELLES, L. V. O brincar e a produção do sujeito infantil. Revista Pátio Educação Infantil, Porto Alegre, n. 3, p. 17-20, dez. 2003/mar. 2004.

FOUCAULT, M. A arqueologia do saber. 7. ed. Rio de Janeiro: Forense Universitária, 2005.

FOUCAULT, M. Microfísica do poder. São Paulo: Graal, 2003.

HORN, M. da G. S. Sabores, cores, sons, aromas: a organização dos espaços na educação infantil. Porto Alegre: Artmed, 2004.

HUIZINGA, J. Homo ludens: o jogo como elemento da cultura. São Paulo: Perspectiva, 2001.

KISHIMOTO, T. M. A LDB e as instituições de educação infantil: desafios e perspectivas. Revista Paulista de Educação Física, São Paulo, supl. 4, p. 7-14, 2001.

KISHIMOTO, T. M. O brincar e a qualidade em uma instituição infantil. Belo Horizonte, Licere, v. 5, n. 1, p. 23-32, 2002. 
KOHAN, W. O. Infância: Entre Educação e Filosofia. Belo Horizonte: Autêntica, 2003.

KUHLMANN JUNIOR, M. A circulação das idéias sobre educação das crianças: Brasil, início do século XX. In: FREITAS, M. C. de; KUHLMANN JUNIOR, M. (Org.). Os intelectuais na história da infância. São Paulo: Cortez, 2002.

LARROSA, J. Tecnologias do Eu e Educação. In: SILVA, T. T. da (Org.). O sujeito da educação. Estudos foucaultianos. Petrópolis: Vozes, 2002.

LIRA, A. C. M. Problematizando o uso dos jogos e das brincadeiras na educação das crianças de 0 a 6 anos: uma análise de propostas exemplares. 2009. 177 p. Tese (Doutorado em Educação)-Universidade de São Paulo, São Paulo, 2009.

MONARCHA, C. Revista do Jardim da Infância: uma publicação exemplar. In: MONARCHA, C. (Org.). Educação da Infância Brasileira (1897-1983). Campinas: Autores Associados, 2001.

PERROTI, E. Confinamento cultural, infância e leitura. São Paulo: Summus, 1990.

RICHTHER, A. C.; VAZ, A. F. Momentos de parque em uma rotina de educação infantil: corpo, consumo, barbárie. Educação e Pesquisa, São Paulo, v. 36, n. 3, set./ dez. 2010. Disponível em: <www.scielo.br>. Acesso em: 23 mar. 2013.

ROCHA, C. M. F. Entre palavras e coisas... infinitos controles. Educação \& Realidade, Porto Alegre, v. 39, n. 1, p. 183-201, jan./jun. 2000.

ROSE, N. Inventando nossos eus. In: SILVA, T. T. da (Org.). Nunca fomos humanos: nos rastros do sujeito. Belo Horizonte: Autêntica, 2001.

Recebido em: 01 de agosto de 2014 Aceito em: 08 de março de 2015 
